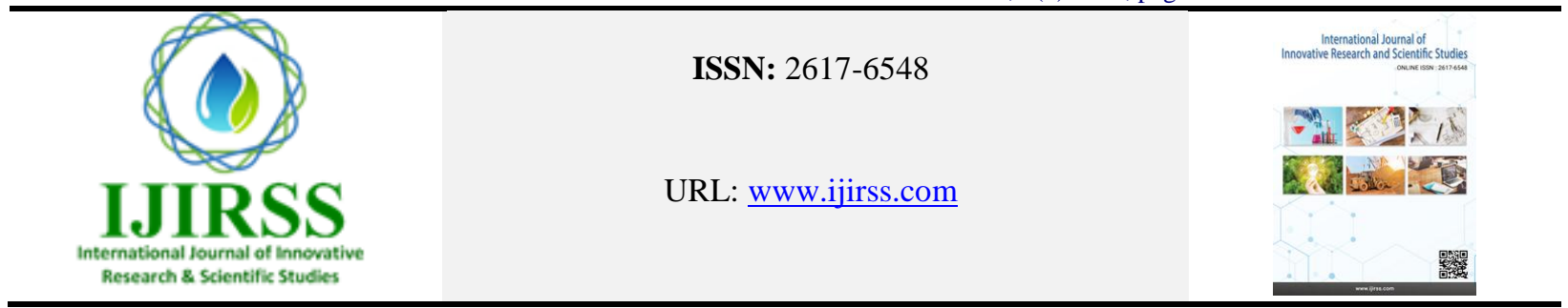

\title{
Essence of Grammar According to Modern Linguistics and Afghan Linguists' Perspectives
}

\author{
Matiullah Hakimi
}

Persian-Dari department, School of Language and Literature, Takhar University, Taliqan, Afghanistan

(Email: mati.hakimi37@gmail.com)

\begin{abstract}
The paper explored views in modern linguistic theories and Afghan linguist perspectives about essence of grammar, its original source, its function in language use and the relationship between mental rules and their description in grammar books. The data were collected from theoretical linguistics, grammar books and 10 Afghan professors who teach linguistics and Persian-Dari grammar in Kabul University via a questionnaire. MS excel was used to analyze the data. The results show the term Grammar refers to a set of constructional rules of a language located in speakers' minds. It is unconscious knowledge which enables speakers of a language to produce and understand its utterances. These mental rules govern composition of phonemes, morphemes, words, phrases, clauses and sentences. Grammar books are like maps of original grammar which has mental essence and describe it. Children learn their native language from elders and their coeval speakers. Second language learners, can learn a foreign language through social interaction and grammar books. Compiling grammatical rules of a language introduces word formation techniques to expand its lexicon, help speakers to know more about their language capacities and possibilities. Grammar books aim to facilitate learning formal language, description of constructional rules, language learning for foreigners and provide correct writing guidelines. The research prescribes grammar teachers to use grammar as means of enrichment of formal language, as it can better function to do its scientific mission.
\end{abstract}

Keywords: Grammar, Language, Speaker, Mind, Mental Rules.

DOI: 10.53894 /ijirss.v4i1.52

Funding: This study received no specific financial support.

History: Received: 11 November 2020/Revised: 24 December 2020/Accepted: 10 January 2021/Published: 3 March 2021

Licensed: This work is licensed under a Creative Commons Attribution 4.0 License (cc) Er

Competing Interests: The author declares that there are no conflicts of interests regarding the publication of this paper.

Transparency: The author confirms that the manuscript is an honest, accurate, and transparent account of the study was reported; that no vital features of the study have been omitted; and that any discrepancies from the study as planned have been explained.

Ethical: This study follows all ethical practices during writing.

\section{Introduction}

Creativity and regularity are significant characteristics of human language. Speakers of each language have knowledge and a system of rules and elements of the language in their mind, which enables them to produce and understand new utterances. This system is called "grammar" [1] Ordinary people consider grammar as books which are used to describe constructional rules of books written by famous authors and well known poets. Often most of educated people even think that only formal language or standard dialect has grammar and is spoken according to grammatical rules. They claim that informal language or dialects of village people in their provinces are not grammatical. In other words, their language doesn't have grammar. However, the fact is that all dialects and languages whether they have writing system or not, have grammar and constructional rules, based on which their speakers interact with one other and interchange messages, wants, feelings and wishes. Each speaker is equipped with knowledge of his/her language that 
enables him/her to produce and comprehend utterances. All speakers learn the grammatical rules of their language in their childhood without conscious and deliberate attempt and formal education. In fact, every child who learns a language, he/she doesn't memorize phrases and sentences he/she hears, rather he/she infers constructional rules from utterances. Therefore, it is a proof for contemporary linguists that all languages have grammar and all speakers of a language know and use grammar of their language [2]. Linguists' duty is to describe language, not to prescribe people how to talk or use their language. A linguist tries to discover more and more rules used in speakers' utterances and describe them without intervention of linguists [3]. The study investigates views of traditional grammarians, and attempts to expose their faults. Furthermore, it explores perspectives of contemporary linguists, in particular Afghan linguists about grammar.

\section{Literature Review}

\subsection{What is Grammar?}

Human language is a creative system. When we learn our native language in our childhood, we can make use of any kind of words, phrases and sentences, in different situations to confront new events. The system of our language has the capacity of interpreting a wide range of senses and facts [2]. According to linguistic views, grammar is not a book and it is not description of rules written in the form of words and sentences. In fact, it is a mental system of rules that enables speakers to produce and understand an unlimited number of utterances, many of them are novel and unfamiliar. Every native speaker of a language is able to produce sentences which are new in their word arrangement and can replace each of the words with ones that are related to the same category. Native speakers of a language also can recognize that certain utterances are not acceptable or cannot be used in their language [4]. Acceptability is the term which characterizes the native speaker's intuitions about the linguistic data [5]. The knowledge that speakers possess of their language is almost entirely unconscious or tacit knowledge. Our knowledge of language appears to be similar to other parts of our mental life. Unconscious phenomena and processes are not psychologically real as conscious ones and the appeal to them is necessary for understanding human cognition [6]. For the most part, the principles and operations of knowledge of language lie outside our consciousness and we cannot analyze or explain what happen when we speak in routine observation

In modern linguistics this ability is called linguistic competence [4]. The study of linguistic competence in modern linguistics focuses on the mental system that allows native speakers to form and interpret sounds, words, phrases and sentences of their language. This system is called grammar and includes the following parts:

Phonetics: containing articulation and perception of speech sounds,

Phonology: constitutes the patterning of speech sounds,

Morphology: formation of words,

Syntax: word arrangement in sentences,

Semantics: combination of sound and meaning or the interpretation of words and sentences [7]. In addition, grammar encompasses form and structure, including meaning and interpretation [2]. The notion of grammar denotes natural hypothesis about what people know about construction of their language. A grammar must achieve descriptive adequacy, it does so, when it corresponds to observations and intuitions of native speakers. It may or may not achieve explanatory adequacy. If a grammar achieve explanatory adequacy, is compatible with acquisition data [8]. A descriptively adequate grammar will not only describe the linguistic data, but also it will contain the general rules and processes that enables the native speakers to produce and interpret sentences in their language. Such grammar is an internal system of principles [5]. Grammar books which are written in different languages, are scientific theories of speakers' linguistic knowledge. Therefore, grammars are something to be tested, corrected, refined and extended like other scientific theories [6]. Thus, the actual grammar is mental rules that lie in speakers' minds.

According to theories of formal grammarians, grammar is a formal system, like turning machines, computer programs, propositional logic, theories of inference and neural nets. A formal system transforms a certain inputs into a particular output. In term of grammar the inputs can be individual symbols like phonemes and the outputs a string of words which constitutes a sentence of formal language [9].

\subsection{Traditional Linguists vs. Modern Linguists}

Traditional linguists in all ancient era thought that some languages have grammar especially those with lots of literary works and written heritage, but most of languages with no writing system and literary works do not have grammars. On the other hand, one of the basic claims of modern linguists is that every language has a grammar system. If a language is spoken, it must have a phonetic and phonological system. As it has words and sentences, it also must have morphology and syntax. Since these words and sentences have systematic meanings, clearly there should be semantic elements used by its speakers. If there is not any system of rules used in a spoken language, obviously speakers cannot communicate with each other [2]. The origin of this fault is derivation of word "Grammar" which is derived from ancient Greek "grammatike" that means "writing signs", because ancient Greek linguists regarded grammar as rules of written language and literary works [10]. Traditional linguists have thought that there were many primitive languages all over the world because their structure systems are very simple, raw and not developed. Contrary to this belief, modern linguistics tells us that all grammars are equal and there is nothing as a good grammar or bad grammar. All grammars do the same thing, they empower speakers to form and interpret the words and sentences of their language. Traditional linguists considered language as a system of steady rules not changing throughout the time. However, according to modern linguistics, language and its structure change over time. With the passage of time, languages change to coordinate its function with new situations in the society. Traditional linguists considered grammar as a set of rules that must be learned in school and used in speaking and writing. On the contrary, in modern linguistics grammar is known as subconscious knowledge which 
is acquired by children in natural settings such as home, street, sport stadium, work place etc. Of course, explanation of grammatical rules helps foreign language learners in better learning.

\subsection{Characteristics of Grammar According To Modern Linguistic Theories}

According to modern linguistic theories, grammar is a generative system of mental rules stored in the brain that enables a speaker to produce utterances and understand utterances other speakers produce. In generative grammar this ability is called linguistic competence [4]. Roots of linguistic competence are genetic in human. The ability to acquire a native language in human kid is like the ability to learn walking or crying [11]. A grammar of expressions is a set of rules that generate the expressions. The guiding hypothesis is that when acquiring their language, people internalize rules of constructing words, phrases and sentences; these internalized rules are called grammar of the language. Grammars which are written and published in form of a book, are regarded as scientific theories that describe the knowledge people have about their language. Like any other scientific theory, a grammar can be tested, extended, refined and revised against the facts [6].

There are two ways of studying language construction, which are called the descriptive and the historical. They differ in that the one views language as being stable and the other views it as being in evolution. Thus, there are two methods of explanation of language structure or two types of grammar; descriptive grammar and historical grammar. Descriptive grammar is the core point of modern linguistics, as it concentrates on description of speakers' unconscious knowledge of their language [12].

\subsubsection{Structural Grammar}

Structuralism is a trend in linguistics, according to which a language is a collective possession of a community. In the mind of each member of such community, the language exists as a system with a determinate structure and the task of a linguist is to work out its structure. Based on views of structural linguists, the history of a language is also essentially the history of its structure and changes that happen overtime [13]. Structural grammar is a new approach in the study of grammar that emphasizes on the role of language structure which constitute conventional pairings of form and meaning. Structural grammar and its theory has root in works of Russian linguist Trubetzkoy and his colleagues in Prague School. They especially worked on phonological structure of language. Structural linguists tried to solve such questions as; how do phonemes relate to, in particular, units of meaning? What kinds of relation does each unit of meaning bear, in turn to other units of meaning? [13].

\subsubsection{Functional Grammar}

Functional grammarian or linguists who are called functionalists, focus on functions of language elements in its construction and on role of language in social activities. According to functional linguists, form of a language is determined by its uses [14]. They consider lexicogrammar, as the core of a language and specifically in the manner that meaning is construed [14]. In this theory Grammar is regarded as architecture of language and speech texts. When people speak or write, they produce texts. The term "texts" refers to any instance of language use, in any medium that makes sense to speakers of the language. Functional grammarians consider text as an instrument that reveals many facts about the system of language in which it is spoken or written [15].

The most noticeable dimension of language is its compositional structure, which is called 'constituency'. Though the meanings of many sentences are constituted from meanings of their component, there are also some sentences that their meanings differ from meanings of the components, such as idioms and proverbs [16]. Language has a hierarchal structure because its constituent elements are based on hierarchy system whereby larger units like words and phrases are made up out of smaller ones as phonemes and morphemes. Halliday refers to such constituency system as 'rank scale' and to each step in the hierarchy as one rank [15]. Based on the constituency system, in Persian language (that may vary in other languages) the smallest unit is phoneme and the largest one is sentence. Phonemes come together to form morphemes; morphemes are combined to make words; words are combined to make phrases; phrases come together to form clauses, and clauses are put together to make sentences. Each of these units is used to correspond to a mental or physical fact.

\subsubsection{Transformational- Generative Grammar}

The most fundamental aim of Transformational-Generative grammar is to reach to a better understanding of language production and process in mind. Chomsky thinks that language is mirror of human mind [1]. According him, the grammar of a language is a device that generates all of its grammatical sequences and none of the ungrammatical ones [17]. Transformational-Generative Grammar focuses on three main fields of linguistics:

Language structure;

Language acquisition;

Language use [7].

A theory of language structure is called grammar, which is concerned with description of a particular language (e.g. English, Persian and French). A grammar of a particular language is a set of rules or principles that tell the speaker how to speak and understand the language. Generative grammarians are eager to find out universal characteristics of human language or construction features that all languages have in common, which is called Universal Grammar. Universal Grammar is abstracted from properties which are common to grammars of particular languages. In other words, Universal Grammar is theory of human language structure [11]. According to Chomsky, Universal Grammar is a theory of abstract properties which are developed from more general properties of successful grammars and successful theories [18]. It deals 
with general properties of a language found everywhere rather than the idiosyncrasies of a particular language such as Persian or English [19].

\subsubsection{Cognitive Grammar}

Cognitive grammarians claim that grammar is meaningful in two respects. First, the elements of grammar -like vocabulary items- have meaning in their own right. In addition, it is a system that enables speakers to construct and symbolize any kind of complicated meanings in forms of elaborate expression. Therefore, it is an essential aspect of the conceptual apparatus through which the speakers apprehend and engage in the world events and human wills. Grammar is an integral part of cognitions as well as a key to understanding it Langacker [20]. According to cognitive linguists, grammar is part of human cognition and has interactions with other cognitive faculties such as thought and memory. Cognitive grammar is symbolic in nature. As a symbol is pairing between a semantic structure and phonological structure and one evokes the other, a lexical item is symbolic because it resides in the pairing between a meaning and a phonological shape. Grammar is a system that combines shape and content to form complex expression [20]. Studying grammar, especially syntax helps us to understand how our minds work and process language units when we communicate and interact with each other, as combining words in sentences is the process of expressing abstract thought [21].

\subsubsection{Afghan Linguists' Perspectives}

Afghan linguists reject classical definition that considers grammar as "technique of correct writing and speaking" because it was a prescriptive approach to study of grammar based on which speakers must learn how to speak and write their language. Contrary to classical view, descriptive approach regards grammar as a set of mental rules that govern language use and production. Yamin (former Professor of linguistics at Kabul University), believes that Grammar is unconscious knowledge of speakers about their language. Contemporary grammarians describe language as it is used not as it must be used [22]. Ilham (the first Afghan linguist who wrote structural grammar of Persian-Dari language), states that "Grammar [book] is a science that describes structure system of a language rules of structural system of a language are discovered and described in grammar [books] [23]. According to Saidi ((former Professor of linguistics and Persian-Dari grammar at Kabul University), in descriptive grammar, rules of spoken language must be described while in classical prescriptive approach written language is studied and introduced as standard method of language use for speakers to be followed in speaking and writing [24]. Traditional grammarians have given examples from former books of Persian poetry while poetry has many limitations for use of words in their ordinary arrangement. In addition, language is dynamic phenomenon and changes over the time. Therefore, we should study rules of contemporary spoken language in grammar books [24].

\subsection{Problem Statement}

Most of educated people even grammar teachers think that grammar of a language is a book containing description of rules about construction of the language which are taught at schools and at universities. They consider grammar books as means of prescribing correct speaking and writing. They also think that only formal language or standard dialect has grammar and is spoken according to grammatical rules. They claim that informal language or dialects of village people in their provinces are not grammatical; it means their language does not have grammar. Though contemporary grammarians in Afghanistan and Iran have written grammar books according to modern linguistic theories and emphasized on descriptive role of grammar, most of Afghan teachers and students do not know about this function of grammar. It is clear that compiling grammatical rules of a language and describing them, has academic advantages, but they are not the same advantages propounded by traditional grammarians.

The present research attempts to give a new vision of grammar essence and its function to Afghan students and teachers who study and teach Persian grammar. The results of this study will show that educated people must consider grammar as means of introducing word formation to extend language lexicon and providing possibilities of interpreting complex senses.

\subsection{Purpose of Study}

The study aims to investigate views of modern linguistic theories and Afghan linguist perspectives regarding the essence of grammar, its original source, its function in production of utterances, word formation and enrichment of language. The study will respond to the following research questions:

What is essence of grammar according to modern linguistics?

Where is the origin of grammatical rules located?

What are the relationships between these rules and grammar books?

What are advantages of compiling grammar of a language?

\section{Methodology}

\subsection{Research Design}

This research is mixed of quantitative and qualitative study. A questionnaire was used to collect data. A descriptive and inferential approach was used to analyze the data. The participants responded to 10 items seeking their views about essence of grammar, its origin, strategies of learning it, the relationship between constructional rules of a language and grammar book. The questionnaire included research questions, with responses which reflected both thoughts of traditional grammarians and views of modern linguistics, to see which perspectives are preferred by Afghan professors. 


\subsection{Participants}

The participants of this study were 10 Afghan professors who teach linguistics and grammar in Persian-Dari department of Kabul University. Two of them were female and the others were male. They had taught linguistics and Persian-Dari grammar for 15 to 35 years.

\subsection{Data Collection Instrument}

A questionnaire was designed through review of literature. The first part of the questionnaire sought information on teaching experiences and major subjects they had taught. The second part aimed to seek views of participants regarding nature of grammar, constructional rules of language, strategy of learning native language and foreign language. Questions of this part were multi responses. The last part consisted of descriptive questions asking the participants about advantages of compiling a language grammar.

\subsection{Data-Collection Procedure}

The questionnaire was shared with Afghan professors. They were asked to fill out the questionnaire and submit it to the author. The author assured them of using their views in research to give students and teachers new vision of grammar. The questionnaires were collected after one week.

\subsection{Data Analysis}

Data were analyzed through Microsoft Excel. Some of the questions were descriptive, the main points of responses were consolidated and the repeated points were omitted.

\section{Results}

The results of descriptive analysis show the impact of teaching linguistic theory in participants' views as they have new vision of grammar. In the following the results of some Afghan linguists' responses to questions about essence of grammar are analyzed in graphs and shown in Figure 5.

\subsection{Nature of Grammar}

The first question asks about fundamental characteristics of grammatical rules?' The question has three answers; 1. Compiled rules in grammar books, 2. Description of constructional rules of a language, 3. A set of mental rules. All participants have chosen the third one which is shown in third column. Figure 1 shows that they all think that grammar is a set of mental rules stored in speakers' minds, which enable them to produce and understand utterances. Question 1: Which of the following characteristics best fit to the nature of grammar?

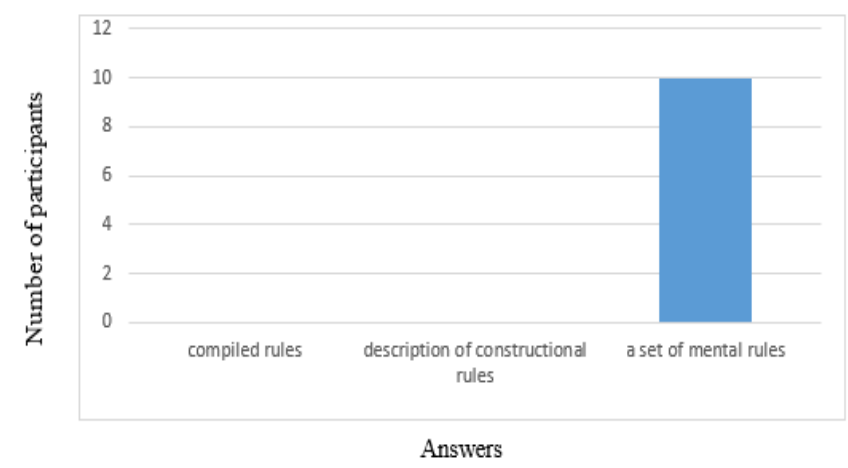

Figure-1.

Nature of grammar.

\subsection{Origin of Grammatical Rules}

The second question asks about the original source of grammatical rules and provides three answers: 1 . Minds of all speakers, 2. Mind of each speaker, 3. Grammar books. As Figure 2 shows, most of participants believe that the original source of a language grammar is minds of its speakers. It means that the complete form of constructional rules of a language cannot be found in individual minds. Question 2: Where is original source of grammar? 


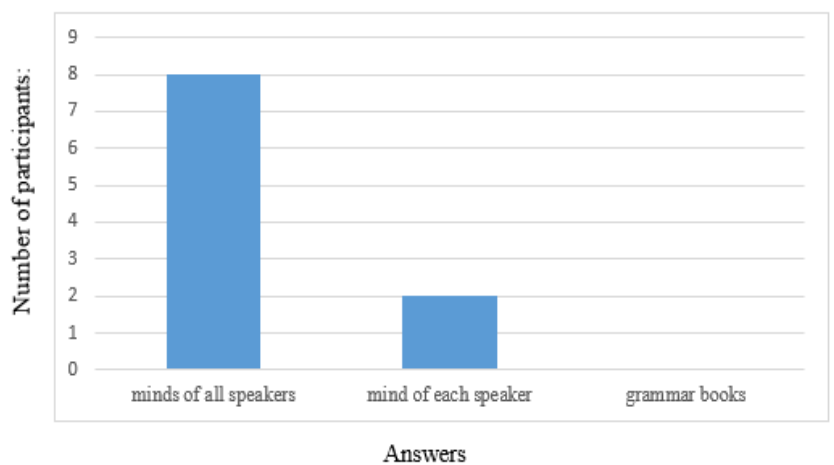

Figure-2.

Origin of grammar.

\subsection{Strategy of Learning Native Language}

The third question asks about the strategy that children use to learn their native language. Three answers were provided: 1. Using grammar books, 2. Listening to their coeval speakers, 3. Listening to elders. As Figure 3 shows, 70 percent of participants think that children learn their native language through listening to adult speakers in their families and 30 percent think that they learn language from their coeval speakers in the society. Question 3: How do children learn grammar of their native language?

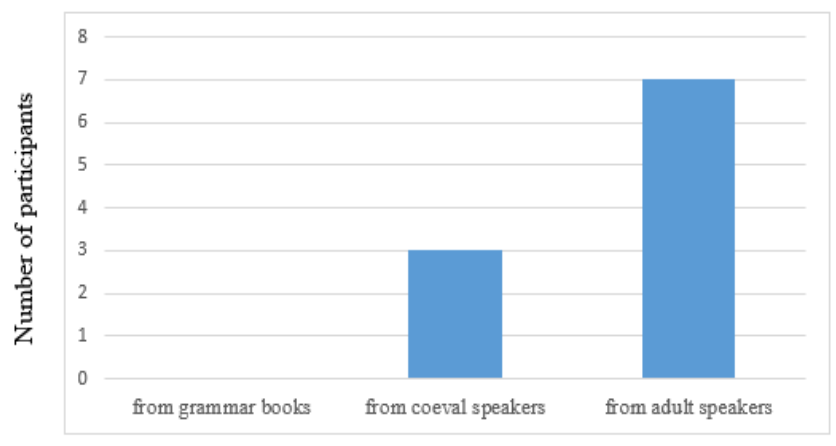

Figure-3.

Strategy of learning native language.

\subsection{Strategy of Learning Second Language}

The fourth question asks about the strategy that second language learners use to learn a foreign language. Three answers were provided: 1. Using grammar books, 2. Through interaction with native speakers, 3. Using both mentioned strategies. Based on the perspectives all participants, second language learners, can learn a foreign language through social interaction with native speakers and through grammar books and second language classes, from their teachers and classmates. It is shown in Figure 4. Question 4: How do learners learn SL grammar?

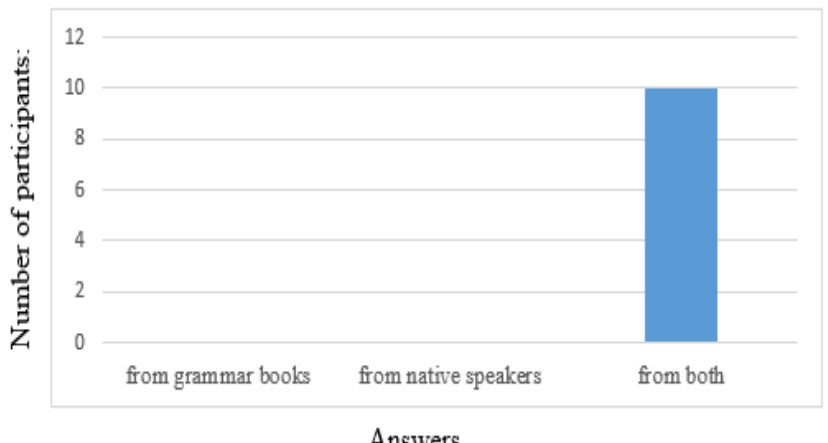

Figure-4.

Answers

Strategy of learning SL.

\subsection{Purposes of Compiling Grammar Books}

The fifth question asks about purposes of compiling grammar books Figure 5. The following objectives were provided to be chosen by participants. They confirmed all objectives as the reasons for compiling grammar books. Grammar books aim to:

- Facilitate learning formal language or standard dialect, 
- Facilitate description of constructional rules,

- Facilitate language learning for foreigners.

- $\quad$ Provide correct writing guidelines.

Question 5: Why do grammarians compile constructional rules of a language?

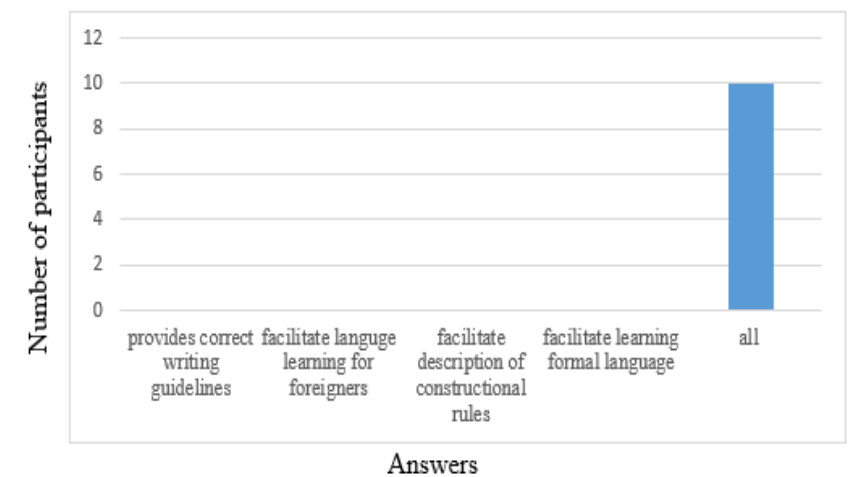

Figure-5.

Goals of compiling grammar rules.

\subsection{Advantages of Compiling Language Grammar}

There was a descriptive question in the questionnaire sought information about advantages of codifying grammatical rules of a language. The following statements show the responses that participants had presented to the questions. Though the original grammar is a mental phenomenon and the books are called "grammar" figuratively, the first usage has become popular in linguistics. Grammar books are somehow like maps to show how constructional rules of language are stored in human mind to be used in speech production and understanding. Writing grammar books and compiling language rules are useful for many respects. Some of them are demonstrated here:

- A grammar book helps speakers to know about different possibilities of a language for explanation of exact contents and interpretation of different senses,

- Strengthens orthography of the written language,

- Facilitates language learning for foreign learners,

- Helps comparative study of two languages,

- Prevents from fast change of language as educated speakers try to imitate formal language patterns,

- Helps scholars in literary studies specially in study of prosody, stylistics, and literary criticism,

- Helps linguists in better study of other branches of linguistics, like etymology, semantics, discourse analysis, and language acquisition,

- Helps lexicography,

- Provides possibilities for language planning and policies,

- Introduces new methods of word formation and extension of language lexicon circle, the point which is mentioned by Farshidward [25].

- Enriches language capacity and presents more methods of interpretation,

- Changes unconscious knowledge of speakers into conscious knowledge,

- Discovers wonders of unconscious knowledge and complicity of language learning.

\section{Discussion}

The present research carried out to explore views propounded in modern linguistic theories and Afghan linguists' perspectives about essence of grammar. The research aimed to find out where the original source of language rules is, how they govern its use and what the relationship between these rules and grammar books is. The study showed that Afghan linguists believe that grammar is a set of constructional rules of a language which are stored in speakers' minds Figure 2. Afghan linguists reject traditional views which consider grammar as a set of prescriptive rules collected in grammar books according to use of language in famous writers and poets' works. Their views are in harmony with modern linguistic theories of grammar Chomsky [1]; Jespersen [12]; and Jackendoff [26] which consider grammar as a mental system of language rules Figure 1. It also shows that grammar is the main part of language faculty and has strong relationship with other parts of human cognition. This result is also in core point of cognitive linguistic studies [20].

The study found out that these mental rules govern composition of phonemes, morphemes, words, phrases, clauses and sentences. This finding confirms the linguistic theory that grammar is a system which controls use of language; production of utterances and understanding others; speech enables speakers of a language to recognize whether a sentence is part of their language or not $[6,26]$. The research also demonstrated that grammar books are like maps of original grammar which has mental essence and describes it. Compiling grammatical rules of a language introduces word formation techniques to expand its lexicon, help speakers to know more about their language capacities and possibilities. Grammar books help researchers to do comparative study of two languages [27]. They are also useful for providing new methods of word formation as it results in extension of language lexicon circle [25]. 


\section{Conclusion}

The paper aimed to explore views in modern linguistic theories and Afghan linguist perspectives about nature of grammar, its original source, its function in language use and the relationships between mental rules and their description in grammar books. The results showed that modern linguistics and Afghan linguists look after language grammar as a creative system of rules. Based on findings creativity and regularity are from significant characteristics of human language. Speakers of each language have knowledge and a system of rules and elements of that language in their mind, which enables them, produce and understand new utterances. This mental system which is constituted from rules and methods of applying them in language is called "grammar". Grammar controls the process of producing and understanding speech sounds, word formation, sentence production, processing and understanding utterances. All speakers have command of their language grammar and this grammatical command enables them to produce new sentences and understand new utterances of others.

The results are contrary to traditional beliefs, all languages have grammar though they differ to some extent. Speakers of each language have learned it unconsciously, but they are not able to describe it. It is the linguist that wants to describe and codify it. The study found out that compiling grammar of a language in its reality, is figuring the mental system of speakers that should be exact and explicit or at least should be proportionate. No grammar book is complete and comprehensive, but it is somehow like efforts made to describe constructional rules of a language. Based on findings of the study, it should be recommended to grammar writers to have descriptive vision of language grammar, show the strategies of word formation and language enrichment and provide guidelines of compiling grammar books for those languages that do not have writing system and literary works.

\section{References}

[1] N. Chomsky, Language and mind, 3rd ed. Cambridge Cambridge University Press, 2006.

[2] W. O'Grady, J. Archibald, M. Aronoff, and J. R. Miller, Contemporary linguistics, 6th ed. New York: Bedford/St Martin's Press, 2010.

[3] G. Sampson, Schools of linguistics. London: Hutchinson, 1980.

[4] N. Chomsky, Aspects of the theory of syntax, 2nd ed. Cambridge, Mass: MIT Press, 1965.

[5] L. Hageman, Introduction to government and binding theory. Massachusetts: Blackwell, 1998.

[6] K. Richard, , Grammar as a science. Massachusetts: Larson, 2010.

[7] A. Radford, Transformational grammar. Cambridge: Cambridge University Press, 1988.

[8] M. Stefan, Grammatical theory. Berlin: Language Science Press, 2018.

[9] L. J. M. Willem, Formal grammar in linguistics and psycholinguistics. Paris: The Hague, 1974.

[10] A. M. S. Pieter, Western linguistics. Persian translation by Ali Mohammad Haqshenas. Tehran: Samt 2010.

[11] A. Radford, Syntax: A minimalist introduction. Cambridge: Cambridge University Press, 1998.

[12] O. Jespersen, The philosophy of grammar. New York: Norton, 2006.

[13] P. Mathews, A short history of structural linguistics. Combridge: Combridge University Press, 2003.

[14] M. A. K. Halliday, On language and linguistics. London: Jonathan Webster, 2003.

[15] M. A. K. Halliday, An introduction to functional grammar. New York: Oxford University Press, 2004.

[16] F. R. Palmer, Semantics, 2nd ed. Cambridge: Cambridge University Press, 2001.

[17] N. Chomsky, Syntactic structures. Mouton: The Hague, 2002.

[18] N. Chomsky, Lectures on government and binding theory. Dordrecht: Farris, 1981.

[19] V. Cook and N. Mark, Chomsky's Universal grammar. Massachusetts: Blackwell, 2007.

[20] W. R. Langacker, Cognitive grammar. New York: Oxford University Press, 2008.

[21] A. Carnie, Syntax. Oxford: Blackwell Publishers, 2001.

[22] M. H. Yamin, Contemporary grammar of Persian-Dari language. Kabul: Maiwand, 1997.

[23] M. H. Ilham, New methods of research in Dari language grammar. By Effort of S. Ali Mohammad Ishraqi. Kabul: Yusofzad, 2012.

[24] M. N. Saidi, Grammar of contemporary Dari language. By Effort of S. Ali Mohammad Ishraqi. Kabul: Yusofzad, 2012.

[25] K. Farshidward, Lengthy grammar of today, 4th ed. Tehran: Sokhan 2013.

[26] S. R. Jackendoff, Foundations of language. New York: University Press, 2003.

[27] G. Arjang, Grammar of today's Persian, 5th ed. Tehran: Qatra 1998. 